\title{
A RELAÇÃO ENTRE EDUCAÇÃO E TRABALHO: UM CONTEXTO DE CONTRADIÇÕES E A APROXIMAÇÃO COM A EDUCAÇÃO PROFISSIONAL
}

\author{
LA RELACIÓN ENTRE EDUCACIÓN Y TRABAJO: UN CONTEXTO DE \\ CONTRADICCIONES Y LA APROXIMACIÓN CON LA EDUCACIÓN \\ PROFESIONAL
}

\section{THE RELATIONSHIP BETWEEN EDUCATION AND WORK: A CONTEXT OF CONTRADICTIONS AND THE APPROACH TO PROFESSIONAL EDUCATION}

\author{
Taise Tadielo CEZAR ${ }^{1}$ \\ Liliana Soares FERREIRA ${ }^{2}$
}

RESUMO: O artigo foi produzido, a partir de um estudo bibliográfico, com a finalidade de apresentar breve reflexão sobre as categorias trabalho e educação, seguida de análise sobre como estas estão inseridas nos discursos da atual política pública de educação profissional, especialmente no documento de criação dos Institutos Federais de Educação, Ciência e Tecnologia - IFS. Foram consideradas para o estudo produções teóricas de autores que vêm estudando sobre estas duas categorias centrais, contextualizadas nos movimentos históricos e políticos da educação profissional no Brasil. Partindo destas leituras, realizou-se análise documental da legislação e textos periféricos que abordam a Lei $\mathrm{n}^{\circ} 11.892$, de dezembro de 2008, a qual institui a Rede Federal de Educação Profissional e Tecnológica e concede nova institucionalidade às Escolas Técnicas Federais e aos Centros Federais de Educação Profissional e Tecnológica, os CEFETs. Tal análise consistiu em conhecer, na tentativa de compreender como e se tal legislação aborda, no interior de seu discurso, as categorias trabalho e educação.

PALAVRAS-CHAVE: Educação. Trabalho. Educação Profissional.

RESUMEN: El artículo fue producido a partir de un estudio bibliográfico, con la finalidad de presentar breve reflexión sobre las categorías trabajo y educación, seguida de análisis sobre cómo estas están inseridas en los discursos de la actual política pública de educación profesional, en especial en el documento de creación de los Institutos Federal de Educación, Ciencia y Tecnología - IFS. Fueron consideradas para el estudio producciones teóricas de autores que han estudiado sobre estas dos categorías centrales, contextualizadas en los movimientos históricos y políticos de la educación profesional en Brasil. A partir de estas lecturas, se realizó un análisis documental de la legislación y de textos periféricos que tratan de la Ley $n^{\circ} 11.892$, de diciembre de 2008, la cual instituye la Red Federal de Educación Profesional y Tecnológica y concede nueva institucionalidad a las Escuelas Técnicas Federales y a los Centros Federales de Educación Profesional y Tecnológica, los CEFETs. El

${ }^{1}$ Pedagoga- TAE, Instituto Federal de Educação, Ciência e Tecnologia Farroupilha, Campus São Vicente do Sul. Mestre em Educação pela Universidade Federal de Santa Maria. taise.cezar@iffarroupilha .edu.br 2 Dr $^{\mathrm{a}}$ Professora, Centro de Educação, Universidade Federal de Santa Maria. anaililferreira@yahoo.com.br 
análisis constituyó en conocer, en el intento de comprender como y si dicha legislación contempla, en el interior de su discurso, las categorías trabajo y educación.

PALABRAS CLAVE: Educación. Trabajo. Educación Profesional.

ABSTRACT: This text was produced from a bibliographical study, which aims to present brief reflection on the categories work and education, followed by an analysis of how these are embedded in the discourse of current public policy on vocational education, especially in the creation document the Federal Institutes of Education, Science and Technology - Ifs. They were considered for the study theoretical productions of authors who have studied on these two main categories, contextualized in historical and political movements of vocational education in Brazil. From these readings, there was documentary analysis of legislation and peripheral texts dealing Law No. 11,892, dated December 2008, which establishes the Federal Vocational and Technological Education Network and provides new institutional framework to Schools Federal Technical and federal Centers for Vocational and Technological Education, the CEFETs. This analysis was to meet in an attempt to understand how and whether such legislation addresses, within his speech, the categories work and education.

KEYWORDS: Education. Work. Professional education.

\section{Considerações iniciais}

O estudo aqui tratado é originado de uma pesquisa durante o mestrado, realizada no ano de 2014, no Programa de Pós-Graduação em Educação, da Universidade Federal de Santa Maria. É objeto central deste texto apresentar breve reflexão sobre as categorias trabalho e educação, seguida de uma análise sobre como estas estão inseridas nos discursos da atual política pública de educação profissional, especialmente no documento de criação dos Institutos Federais de Educação, Ciência e Tecnologia - Ifs.

Portanto, este trabalho é fruto de um estudo bibliográfico, o qual analisou produções teóricas de autores que vem estudando sobre estas duas categorias centrais, trabalho e educação, considerando os movimentos históricos e políticos da educação profissional na educação brasileira. Partindo destas leituras, realizou-se análise documental da legislação e textos periféricos que abordam a Lei $\mathrm{n}^{\circ} 11.892$, de dezembro de 2008, a qual institui a Rede Federal de Educação Profissional e Tecnológica e concede nova institucionalidade às Escolas Técnicas Federais e aos Centros Federais de Educação Profissional e Tecnológica, os CEFETs. Tal análise consistiu em conhecer, na tentativa de compreender como e se tal legislação aborda no interior de seu discurso as categorias trabalho e educação. 
Vale ressaltar que este processo de estudo se constituiu a partir da perspectiva teórica e metodológica do materialismo histórico-dialético, pois, compreende-se tal abordagem como um processo dinâmico de conhecer a concreticidade da realidade, considerando a materialidade histórica da sociedade. Um método de produção científica de transformação dos fenômenos reais, por meio da reprodução subjetiva e intelectual do desenvolvimento e explicitação desta realidade, a partir da atividade prática objetiva dos seres humanos como sujeitos históricos (KOSÍK, 1976, p 16). É fundamental reconhecer a realidade como uma construção histórica, que apresenta questões vitais a serem estudadas, considerando a educação e o trabalho como processos constituintes dos seres humanos. Nesse sentido, é premente pensar a atualidade da educação como um fenômeno real na sociedade, a qual historicamente se constituiu nas relações sociais e de produção, sob aspectos culturais, políticos e econômicos. Desta maneira, não está constituída somente pela individualidade dos sujeitos.

Este texto, portanto, apresenta brevemente a partir de uma abordagem teórica bibliográfica questões conceituais que levem à reflexão sobre as categorias trabalho e educação, no contexto histórico-social das políticas públicas de educação profissional e tecnológica. A seguir, é contemplada a discussão sobre a atualidade de tais políticas, na qual está o reordenamento institucional demarcado pela implantação dos Institutos Federais. Por fim, são apresentadas, à guisa de conclusão, considerações finais provisórias sobre o assunto tratado.

\section{Uma breve revisão teórica sobre trabalho e educação}

Em texto apresentado na $29^{\mathrm{a}}$ Reunião da Associação Nacional de Pós-Graduação e Pesquisa e Educação (ANPED), “Trabalho e Educação: fundamentos ontológicos e históricos"3, publicado na Revista Brasileira de Educação, Saviani argumenta que "Trabalho e educação são atividades especificamente humanas. Isso significa que, rigorosamente falando, apenas o ser humano trabalha e educa" (2007, p. 152). Assim, o autor propõe a necessidade de conceber o ser humano para além do que classicamente é considerado e cristalizado no senso comum, em que o atributo essencial é dado pela racionalidade que caracteriza a espécie humana. Ora, esta não é suficiente para definir a

${ }^{3}$ http://www.scielo.br/scielo.php?script=sci_arttext\&pid=S1413-24782007000100012\&lng=pt\&nrm=iso\&tlng=pt Acessado em 16 de janeiro de 2013. 
essência humana. Esta visão é contraposta à existência histórica dos sujeitos, que "se adaptam à natureza" e "têm de adaptar à natureza a si", desta forma transformando a natureza, ajustando-a as próprias necessidades, se pode entender este processo como trabalho.

Ora, o ato de agir sobre a natureza transformando-a em função das necessidades humanas é o que conhecemos com o nome de trabalho. Podemos, pois, dizer que a essência do homem é o trabalho. A essência humana não é, então, dada ao homem; não é uma dádiva divina ou natural; não é algo que precede a existência do homem. Ao contrário, a essência humana é produzida pelos próprios homens. O que o homem é, é-o pelo trabalho. A essência do homem é um feito humano. É um trabalho que se desenvolve, se aprofunda e se complexifica ao longo do tempo: é um processo histórico. (SAVIANI, 2007, p. 154)

Nas comunidades mais primitivas, quando não existiam classes divididas, trabalho e educação aconteciam de maneira intrínseca, em "uma relação de identidade", uma vez que os sujeitos humanos aprendiam a produzir sua existência, aprendiam a trabalhar trabalhando, se apropriavam de maneira coletiva dos meios de produção da existência e neste movimento, acontecia uma educação em processo.

No entanto, a partir do momento em que, no desenvolvimento da produção, persistiu o modelo capitalista, acarretou na apropriação privada da terra e com isso a divisão do trabalho. Desse modo, a sociedade moderna sofreu a divisão dos seres humanos em classes, como Marx (2012) no séc. XIX anunciava: a classe dos proprietários e a dos não proprietários. Este acontecimento impactou na história da humanidade e, por conseguinte, nas relações sociais e de produção, coexistindo uma sociedade formada por dominados e dominantes, possibilitando a existência de uma classe que "vive" do trabalho alheio, daqueles que vendem sua força de trabalho, "do trabalho dos não-proprietários que passaram a ter obrigação de, com o seu trabalho, manterem-se a si mesmos e ao dono da terra, convertido em seu senhor.” (MARX, 2012, p.155).

Este contexto vem se perpetuando até os dias de hoje, intensificado pelo avanço do capitalismo, o que gerou antagonismos em todos os processos da sociedade de uma maneira geral. Com implicações nas dimensões da economia, da cultura, das formas de produção, da educação e também, o mundo do trabalho é profundamente modificado. A compreensão sobre classe social a partir do anúncio de Marx (2012), como mencionado anteriormente. também é afetada. 
É possível perceber algumas consequências decorrentes dessas mudanças, especialmente a partir da década de 1980, em que o próprio sentido de trabalho sofre transformações, decorrentes de processos como: o avanço tecnológico, as formas transitórias e flexibilizadas de produção, o desemprego estrutural, entre outros. Antunes (2011) descreve bem este processo, localizando alguns países que demarcaram fatores relevantes:

\begin{abstract}
Comecemos enumerando algumas das mudanças e transformações ocorridas nos anos 80. Em uma década de grande salto tecnológico, a automação, a robótica e a microeletrônica invadiram o universo fabril, inserindo-se e desenvolvendo-se nas relações de trabalho e de produção do capital. Vive-se no mundo da produção, um conjunto de experimentos, mais ou menos intensos, mais ou menos consolidados, mais ou menos presentes, mais ou menos embrionários. $\mathrm{O}$ fordismo e o taylorismo já não são únicos e mesclam-se com outros processos produtivos (neofordismo, neotaylorismo, pós-fordismo), decorrentes das experiências da "Terceira Itália", na Suécia (na região de Kalmar, do que resultou o chamado Kalmarnianismo), do Vale do Silício nos EUA, em regiões da Alemanha, entre outras, sendo em alguns casos até substituídos, como a experiência japonesa a partir do toyotismo permite constatar. (ANTUNES, 2011, p. 23)
\end{abstract}

Com tal leitura, verifica-se que nessa globalização emergem novos processos de trabalho, que acabam por constituir múltiplas faces para esta atividade humana, e ainda, segundo o autor (2011, p. 23), o mundo do trabalho passa por metamorfoses. Constatase um processo contraditório chamado de desemprego estrutural, uma vez que se presencia a redução do operariado industrial, fabril, manual, especialmente nos países de capitalismo avançado. Ao mesmo tempo, é ampliado o trabalho assalariado, precarizado, desregulamentado, parcial, temporário, subcontratado, "terceirizado", especialmente no setor de serviços, configurando ainda um contexto de "economia informal". Começa também um movimento de inserção das mulheres no mundo do trabalho, que também passa a incorporar as pessoas mais jovens e excluir os mais velhos. É destacado que "Há, portanto, um processo de maior heterogeneização, fragmentação e complexificação da classe trabalhadora” (ANTUNES, 2011, p. 47).

Com todos estes fatores, faz-se necessário pensar sobre o lugar e o espaço da educação nestes processos, e, desta maneira, tentar compreender qual a sua relação com o mundo produtivo, a sua relação com classes sociais. É mister reconhecer que assim como existe a divisão do trabalho, a educação também, consequentemente, se tornou dicotômica, separando-se das dimensões do trabalho e, em consequência, está localizada 
a origem da escola. Conforme Saviani (2007, p.155), o "processo de institucionalização da educação, correlato do processo de surgimento da sociedade de classes, que por sua vez, tem a ver com o processo de aprofundamento da divisão do trabalho".

Com os movimentos e crises cíclicas do capitalismo, a educação ganha um valor econômico, sendo considerada como um bem de produção, observando a relevância em "qualificar os recursos humanos". Esta é uma visão produtivista da educação, propagada a partir da segunda metade do século XX, permeada por princípios da racionalidade e com caráter tecnicista. No Brasil, implicou sucessivas reformas educativas com base nos preceitos neoliberais, os quais compreendem na ação do Estado em conformidade como os interesses dominantes, no esforço em conquistar o máximo de resultados com o menor dispêndio (SAVIANI, 2005). ${ }^{4}$

Mészaros (2008), na obra “A educação para além do capital”, faz uma crítica à lógica do capital e aborda sobre seu impacto na educação, considerando que não se pode negar o fato da ligação entre os processos educacionais e os processos sociais. $\mathrm{O}$ autor defende a premissa de que não se pode conceber uma reformulação significativa da educação sem uma transformação no contexto social em que acontecem as práticas educacionais, uma vez que elas próprias também exercem funções de mudança. Desta forma, está posta uma contradição, pensar em reformas quando a lógica dominante é a própria lógica da estrutura do sistema do capital.

\begin{abstract}
A educação institucionalizada, especialmente nos últimos 150 anos, serviu - no seu todo - ao propósito de não só fornecer os conhecimentos e o pessoal necessário à máquina produtiva em expansão do sistema do capital, como também gerar e transmitir um quadro de valores que legitima os interesses dominantes, como se não pudesse haver nenhuma alternativa à gestão da sociedade, seja na forma "internalizada" (isto é, pelos indivíduos devidamente educados) ou através de uma dominação estrutural e uma subordinação hierárquica e implacavelmente imposta. (MÉSZÁROS, 2008, p. 35)
\end{abstract}

Com relação à educação institucionalizada, Saviani (2007) apresenta um resgate histórico sobre o conceito de instituições escolares no Brasil, considerando a diversidade de significados ${ }^{5}$ dessa palavra. "Instituição" remete a pensar que esta é uma estrutura material criada como unidade de ação, organizada, constituída pelos sujeitos

\footnotetext{
${ }^{4}$ Capitalismo, trabalho e Educação / José Caludinei Lombardi, Demesrval Saviani, José Luis Sanfelice (orgs.). - 3. ed. - Campinas, SP: Autores Associados, HISTEDBR, 2005.

5 A palavra "instituição" deriva do latim institutio, onis. Este vocábulo apresenta uma variação de significados que podem ser agrupados em quatro acepções: "1. Disposição; plano; arranjo. 2. Instrução; ensino; educação. 3. Criação; formação. 4. Método; sistema; escola; seita; doutrina" (TERRINHA, 1945 apud, SAVIANI, 2007, p.3)
} 
para atender a determinada necessidade humana com caráter permanente. Necessariamente é social, portanto uma instituição é criada para permanecer.

No entanto, é sabido que existem necessidades que são transitórias. Assim, em uma observação primeira e mais genérica, poderia se dizer que não se justifica a criação de uma instituição para suprir uma necessidade que é passageira, que, à medida que é satisfeita, tal instituição é desfeita. Porém, as instituições, como todos os produtos humanos, são históricas, não podendo assim deixar de denotar um caráter transitório. "Mas sua transitoriedade se define pelo tempo histórico e não, propriamente, pelo tempo cronológico e, muito menos, pelo tempo psicológico". (SAVIANI, 2007, p. 5)

Partindo destas concepções é pensado sobre o percurso transcorrido pelas instituições de Educação Profissional no Brasil em sua totalidade, como produto de um processo histórico e social, de caráter transitório, que se modifica, se reestrutura à medida que vão se estabelecendo relações conforme a realidade, podendo estas ser de ordem econômica, produtiva, política, cultural, entre outras. Compreende-se por "Totalidade", a partir do que destaca Ciavatta (2007):

Na perspectiva marxista, a totalidade é um conjunto de fatos articulados ou o contexto de um objeto com suas múltiplas relações, ou, ainda, um todo estruturado, mas aberto a novas determinações, que se desenvolve e se cria como produção social do homem (CIAVATTA, 2007, p.24).

Nesse sentido, é fato que a educação não deixa de ser implicada pelo mundo do trabalho e pela lógica política e econômica que engendra a sociedade moderna, na qual atualmente as ideias neoliberais assumem posição progressiva nos processos de construção e implementação de políticas públicas. No desenvolvimento capitalista em meados da década de 1980 e 1990, o crescimento econômico é marcado de maneira acirrada e, nesse contexto, a relação entre os processos de produção e a educação tornam-se chave, em que ideologicamente se atribui à escola uma função econômica fundamental. (GENTILI, 2005).

Vale pensar que tais políticas são implicadas por determinadas demandas, as quais geram novas estruturações e configurações nos contextos sociais e pedagógicos das instituições, fazendo assim com que estas tenham necessidades transitórias numa condição estrutural permanente. É o que se constata ao analisar o desenho histórico apresentado abaixo, o qual remete a uma melhor visão das mudanças institucionais sofridas pela Educação Profissional: 
Figura 11: Cronologia das mudanças institucionais da Educação Profissional no Brasil.

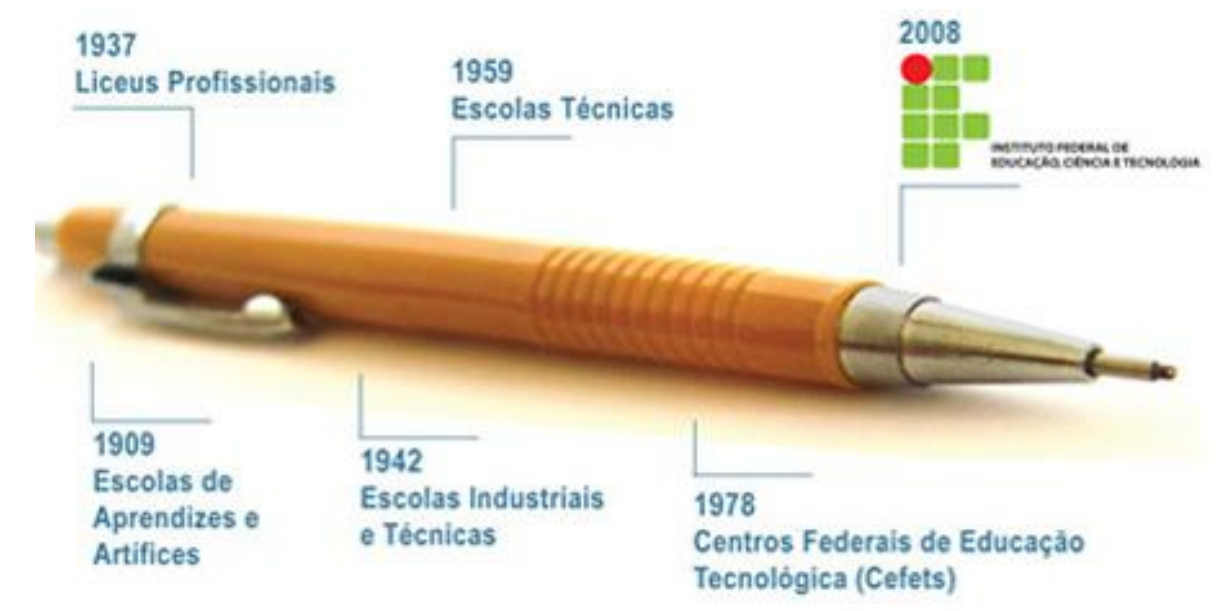

Fonte: Redefederal.mec.gov.br

Desde a primeira estrutura escolar pública criada no âmbito da Educação Profissional, em 1909, é possível perceber as diversas mudanças na institucionalidade das mesmas até se chegar à estrutura de Instituto a qual se tem atualmente, bem como à oficialização de um sistema de ensino nacional para a Educação Profissional e Tecnológica, com a formação da Rede.

A Educação Profissional sempre foi um campo complexo, com muitos embates políticos. E as instituições de educação são demandadas pela globalização em que se vive, esta forma polissêmica, até mesmo ideológica, da realidade política e econômica do capital nesta sociedade contemporânea (RUMMERT, ALGEBAILE e VENTURA, 2011). ${ }^{6}$

Kuenzer (2006), em uma significativa pesquisa, estudou as políticas de Educação Profissional da última década, compreendendo os anos de 1995 e 2005, considerando os governos dos presidentes Fernando Henrique Cardoso e Luís Inácio Lula da Silva. Neste estudo, a autora confrontou tais políticas com as atuais demandas da classe trabalhadora, mediante as transformações que aconteceram no mundo do trabalho no regime de acumulação flexível, no sentido de compreender as estratégias de inclusão subordinada, ou seja, as estratégias que dizem respeito ao discurso da inclusão dos trabalhadores no mundo do trabalho por meio da qualificação profissional.

Percebe-se também que a Educação Profissional como um nível da educação brasileira é, historicamente, negligenciada como parte da educação pública brasileira,

${ }^{6}$ Ver texto "Educação e formação humana no cenário de integração subalterna no capital imperialismo". <http://www.uff.br/ejatrabalhadores/ANPEmD .pdf $>$. 
desde a origem, em sua organização nacional como preparação para o trabalho. Tal fato vem sendo revelado por alguns autores $(\text { as })^{7}$ que abordam sobre a mesma no Brasil e que constituem um panorama histórico da estruturação e do desenvolvimento da Educação Profissional no país, tanto no âmbito escolar como não escolar. Também é relevante o crescente interesse por abordagens que investigam as relações entre trabalho e educação, muitas destas sob o aporte marxista, uma vez que este parece oferecer uma possibilidade de estudos histórico-críticos, os quais impliquem uma compreensão real das tensões e dos desafios que emergem dos processos políticos e pedagógicos atualmente realizados.

Manfredi (2002) realizou um resgate histórico e crítico da Educação Profissional no Brasil, inicialmente revisando conceitos extremamente valiosos para a compreensão desta educação, como: trabalho, profissão e escolarização. Apresenta, em seu pensamento, a premissa de que a "constituição da escola não esteve vinculada à formação para o trabalho" (MANFREDI, p. 51, 2002). A sociedade segmentada em classes, e, nela, a educação escolar institucionalizada, também se estrutura de maneira dual, em que, no princípio, era destinada a preparar as pessoas da classe dominante, a formação daqueles que exerciam o poder. Já a formação para o trabalho, por muito tempo, aconteceu nos movimentos da vida social e comunitária, paralelamente às próprias atividades de trabalho, em um processo informal, não institucionalizado. É a partir deste contexto histórico, político e cultural brevemente citado, que se promoveu um distanciamento entre escola e a sociedade, as práticas que acontecem no mundo real (concreto) do trabalho e as práticas que se constituem na instituição escolar.

Desta maneira, a complexidade dos processos de reordenamento institucional atravessa o fazer cotidiano das atuais instituições de Educação Profissional, e, agora, tecnológica. Considera-se também que a dimensão "tecnológica" foi agregada ao termo Educação Profissional no curso da História da Educação no Brasil, em detrimento das próprias demandas da globalização e facetas apresentadas pela evolução do capitalismo na sociedade em proporções mundiais, como, por exemplo, a divisão social do trabalho e a modernização tecnológica. Tem que ser reconhecido que existe um imaginário social o qual concebe "a escola como uma instituição que tem por função preparar os jovens para o mercado de trabalho" (MANFREDI, p. 51, 2002).

${ }^{7}$ Saviani (2011), Manfredi (2002), Frigotto; Ciavatta (2002), Lombardi; Saviani; Sanfelice (2005), entre outros. 
Observando este contexto das políticas públicas de educação e multiplicidade de programas destinados à Educação Profissional, à Educação de Jovens e Adultos que vivem no mundo do trabalho, é possível notar a diversidade de intenções políticas e pedagógicas em vigência atualmente, gestadas pelo governo, por meio da Secretaria de Educação Profissional e Tecnológica (SETEC) do Ministério da Educação (MEC). Reflete-se nos Institutos Federais de Educação tal multiplicidade, uma vez que são múltiplas as ações a que a mesma instituição se destina, considerando projetos de ensino que compreendem tanto cursos de curta duração, até cursos em nível de educação básica, nível superior e pós-graduação. Para tanto, segue reflexão, com base no contexto histórico social da educação, sobre a atualidade institucional da educação profissional e tecnológica, a qual aparenta no texto legal estar no revés de práticas pedagógicas que consolidem uma relação entre trabalho e educação.

\section{A atualidade das políticas públicas de Educação Profissional: sob uma nova institucionalidade}

No interior das instituições há um quebra-cabeça a ser decifrado. Uma vez dentro da instituição, trata-se de se fazer o jogo das peças em busca dos seus respectivos lugares. Legislação, padrões disciplinares, conteúdos escolares, relações de poder, ordenamento cotidiano, uso dos espaços, docentes, alunos e infinitas outras coisas ali se cruzam. Pode-se dizer que uma instituição escolar ou educativa é a síntese de múltiplas determinações, de variadíssimas instâncias (política, econômica, cultural, religiosa, da educação geral, moral, ideológica etc.) que agem e interagem entre si, "acomodandose" dialeticamente de maneira tal que daí resulte uma identidade. (SANFELICE,2007)

Os Institutos Federais de Educação, Ciência e Tecnologia foram criados a partir da agregação e transformação de antigas instituições de educação profissional, como as Escolas Técnicas Industriais e Agrícolas e os Centros Federais de Educação, Ciência e Tecnologia. Estes são construídos na perspectiva de serem um novo modelo políticopedagógico de instituição de Educação Profissional e Tecnológica. Observando sua estruturação multicampi e pluricurricular, em uma primeira leitura, parece intencionar um rompimento com o caráter pragmático e circunstancial da Educação Profissional até então desenvolvida, durante um ciclo que refletiu crises também na educação, por ter um conteúdo ideológico caracterizado no individualismo e na competitividade. 
Pacheco $(2011)^{8}$, na obra "Institutos Federais: uma revolução na Educação Profissional e Tecnológica", relata o processo de expansão da Educação Profissional, contextualizando o surgimento dos Institutos Federais na atualidade, considerando que a definição identitária desta instituição deve se constituir a partir de sua localização territorial e das orientações sobre modelo pedagógico, o qual concebe uma organização pedagógica que inter-relaciona diferentes níveis de ensino e cursos ofertados, desde a Educação Básica até a Pós-Graduação.

Partindo de tal entendimento sobre esta instituição nascente, foi realizada uma leitura de materiais publicados pelo Ministério da Educação, os quais possibilitam conhecer as ideias que pautam as diretrizes desta instituição. É possível perceber certo otimismo e ousadia em tais ideias, uma vez que intencionam a construção de uma educação como "instrumento de transformação na sociedade", a qual é pensada segundo as exigências do mundo atual. Pacheco e Silva (2009), gestores da Secretaria de Educação Profissional e Tecnológica nos anos de 2005 até 2009, ao escreverem a nota introdutória para o texto: Institutos Federais, Lei 11.892, de 29/12/2008: Comentários e Reflexões, fazem a seguinte consideração:

A proposta dos institutos federais entende a educação como instrumento de transformação e de enriquecimento do conhecimento, capaz de modificar a vida social e atribuir maior sentido e alcance ao conjunto da experiência humana. É nesse sentido que deve ser pensada segundo as exigências do mundo atual, concorrendo para alterar positivamente a realidade brasileira. (PACHECO; SILVA, 2009, p. 10)

No entanto, faz-se necessário pensar se esta educação pretendida, na maneira como está projetada e sendo efetivada, tende a superar ou fortalecer a ordem econômica e social, bem como as formas de produção legitimadas até os dias de hoje? Certamente esta questão não será totalmente respondida neste momento, no entanto são ressaltados aspectos que poderão ser explorados com maior profundidade em outras oportunidades.

$\mathrm{Na}$ análise sob as finalidades e características presentes na Lei $\mathrm{n}^{\circ} 11.892$, de 2008, que orientam a criação dos institutos federais, foi destinada atenção para os elementos referentes às categorias trabalho e educação, primeiramente pelo presente estudo estar orientado pela perspectiva teórica e metodológica do Materialismo

${ }^{8}$ Referência a Eliezer Pacheco, Secretário de Educação Profissional e Tecnológica (SETEC) nos anos de 2005 a 2012. 
Histórico e Dialético, considerando que estas duas categorias encontram-se historicamente amalgamadas na legitimação das políticas públicas. No entanto, é primordial salientar a dificuldade em analisar, especificamente, estas categorias, uma vez que foi preciso desviar o olhar para outras questões que se tornam frequentemente repetidas na própria lei e nos demais textos que foram lidos.

A categoria trabalho aparece subentendida em algumas partes destes outros textos periféricos à legislação, os quais dão sustentação teórica para ela, constando que este é concebido como "organizador do processo educativo [...]. O reconhecimento do trabalho como experiência humana primeira, organizadora do processo educativo" (PACHECO; SILVA, 2009, p. 10). Pode-se entender que este pressuposto tem uma fonte teórica primeira no pensamento marxiano, o qual intencionava “[...] introduzir um novo tipo de ensino, unindo o trabalho manual ao intelectual” (MARX, 2004, p. 13).

Para pensar de maneira mais crítica sobre o aspecto de conceber o trabalho como princípio educativo, baseia-se em Ciavatta (2005), a qual apresenta em forma de artigo um estudo realizado que objetivava reconhecer os processos de mudança da sociedade capitalista e seu impacto no trabalho, bem como a relação destas mudanças com o conhecimento e os processos de formação. A partir disso, a autora desenvolve uma pesquisa sobre escolas que preparavam para o trabalho, escolas profissionais das três primeiras décadas do século XX, examinando algumas mediações do mundo do trabalho, considerando a "escola do trabalho" e a educação dos trabalhadores. Trata-se, pois, de compreender que não se tem um conceito único para "escola do trabalho", uma vez que a cada época ela assume uma função variada, específica do seu tempo histórico “e realiza-se, no campo educacional como uma das múltiplas dimensões do trabalho na vida humana" (CIAVATTA, 2005, p. 122).

Mais do que um termo singelo, a "escola do trabalho", deve ser entendida como processo social complexo, agir humano, movimento de idéias e ações que acompanham a introdução do trabalho na escola como um princípio educativo. (CIAVATTA, 2005, p. 126)

É possível observar que o Instituto, de modo geral, requer uma profissionalização, no âmbito da ciência e da tecnologia, pois existe um "compromisso" com o desenvolvimento das mesmas. Outro aspecto interessante observado e muito frequente em vários itens da lei é a presença permanente do termo "desenvolvimento" 
ligado à inovação tecnológica, às questões socioeconômicas locais, regionais e nacional. Podemos citar o Art.6 $6^{\circ}$, itens I e IV:

I - ofertar educação profissional e tecnológica, em todos os seus níveis e modalidades, formando e qualificando cidadãos com vistas na atuação profissional nos diversos setores da economia, com ênfase no desenvolvimento socioeconômico local, regional e nacional;

IV - orientar sua oferta formativa em benefício da consolidação e fortalecimento dos arranjos produtivos, sociais e culturais locais, identificados com base no mapeamento das potencialidades de desenvolvimento socioeconômico e cultural no âmbito de atuação do Instituto Federal [...]. (BRASIL, 2008)

Conforme a análise, identificou-se no Art. $7^{\circ}$ da lei uma multiplicidade de objetivos a serem desenvolvidos por esta instituição. No momento, não foi possível realizar uma análise mais profunda sobre cada um, no entanto, foi realizada uma leitura geral para se ter conhecimento sobre os mesmos. São objetivos dos institutos o ensino, a pesquisa e a extensão, por meio da oferta de: cursos de Educação Profissional Técnica de Nível Médio (prioritariamente na forma de cursos integrados, contemplando o público da educação de jovens e adultos); cursos de formação inicial e continuada de trabalhadores (voltados para a capacitação, o aperfeiçoamento, a especialização e a atualização de profissionais, em todos os níveis de escolaridade, nas áreas da educação profissional e tecnológica); desenvolver pesquisas aplicadas (priorizando as dimensões técnicas e tecnológicas, de maneira que seus benefícios estejam à disposição da comunidade); promover atividades de extensão de acordo com os princípios e finalidades da educação profissional e tecnológica (em articulação com o mundo do trabalho e os segmentos sociais, e com ênfase na produção, desenvolvimento e difusão de conhecimentos científicos e tecnológicos); estimular e apoiar processos educativos que levem à geração de trabalho e renda e à emancipação do cidadão na perspectiva do desenvolvimento socioeconômico local e regional; e ministrar em nível de educação superior cursos superiores de tecnologia, cursos de licenciatura (especialmente nas áreas de ciências da natureza, matemática e para educação profissional), cursos de bacharelado e engenharia, cursos de pós-graduação lato sensu de aperfeiçoamento e especialização e cursos de pós-graduação stricto sensu de mestrado e doutorado (BRASIL, 2008).

É destacada, como finalidade da Educação Profissional e Tecnológica sob a atual política, que sua oferta como processo educativo e investigativo esteja atrelada à 
geração e à adaptação de soluções técnicas e tecnológicas, em benefício do fortalecimento dos arranjos produtivos, sociais e culturais locais, a partir do mapeamento de potencialidades, como consta no Art. $6^{\circ}$, item II. Dessa maneira, é proposto que os Institutos a realizem e estimulem a pesquisa aplicada, a produção cultural, o empreendedorismo, o cooperativismo, o desenvolvimento e a transferência de tecnologias sociais. É observada também a função dos Institutos com relação à formação de professores, uma vez que esta instituição deve ofertar cursos de licenciatura na área de Ciências da Natureza e Matemática, bem como pode oferecer capacitação técnica e atualização pedagógica para professores da rede pública.

As leituras dos textos paralelos (Silva, 2009 e Pacheco, 2011) à realização da análise da lei apontam para a necessidade de promover formação continuada de trabalhadores ao longo da vida, sendo potencializadora para os indivíduos no desenvolvimento da autonomia e de capacidades de questionamento e interação com a realidade. É percebido um discurso sobre a democratização do conhecimento científico e tecnológico, garantindo, por meio destes, condições favoráveis à inserção e à permanência das pessoas no trabalho, assim como à geração de trabalho e renda. Portanto, a atuação dos Institutos Federais está atrelada à qualificação profissional do trabalhador, em que, por meio da formação dos itinerários formativos, promove-se a elevação da escolaridade das pessoas.

Ao detalhar esse contexto que se torna tão diverso e complexo no campo da política pública da Educação Profissional, é preciso enxergar para além do discurso oficial, uma vez que é atribuída para a educação uma função "estratégica" na "expansão do desenvolvimento socioeconômico e tecnológico" da sociedade, como os próprios gestores anunciam.

Conforme Fogaça (2003), essa relação entre "inovação tecnológica, educação e qualificação" foi intensificada a partir dos anos da década de 1970, especialmente nos países industrializados ou em processo de industrialização, fatores estes que impactaram em reformas dos sistemas educacionais. Em decorrência dessa industrialização, novos perfis ocupacionais emergiram e, com isso, a formação escolar foi requisitada para mudar. Tendo em vista a necessidade de preparar as pessoas para esse novo contexto da produção capitalista, por isso a escola assume a função na qualificação profissional básica.

Lucena (2008), no texto "Marxismo, crise do capitalismo monopolista e qualificação dos trabalhadores", após realizar um resgate teórico a partir das concepções 
marxiana e marxista sobre a crise do capitalismo, apresenta uma importante consideração sobre as relações entre o modo de produção e a formação dos trabalhadores. É pontuada primeiramente uma contradição existente, sobre o fato de que a aceleração no tempo de produção das mercadorias implica a aceleração no tempo de formação dos trabalhadores que irão produzir tais mercadorias. Dessa maneira, este autor defende que a formação de trabalhadores se constitui em processos além de contraditórios, também ideológicos.

\begin{abstract}
Ideológicos, ao omitir que em um processo de crise, os homens de negócios se tornam mais seletivos em virtude do aumento do exército de reserva. Ideológicos, ao apontar que a maior formação intelectual exigida é homogênea, quando na realidade varia de região para região do pais, dependendo do potencial escolar oferecido regionalmente. Ideológicos, ao omitir que o trabalhador com o maior nível de escolaridade para a ter a sua força de trabalho sobreexplorada nas empresas. Contraditórios por proporcionar que a elevação da escolar de um trabalhador corresponda ao desemprego de outro trabalhador, uma vez que as empresas não mais necessitam contratar no mercado, profissionais, pois já os possuem em um processo multifuncional, elevando tanto a mais-valia absoluta como a relativa. Contraditórios por defender o aumento do nível de escolaridade dos trabalhadores por meio da inserção na ciência e atuar no movimento oposto do neotaylorismo, uma dimensão ampliada e alienante que concentra a produção científica e tecnológica em patamares decisivos como pouco se ouviu na história do capitalismo. (LUCENA, 2008, p. 197)
\end{abstract}

O atual contexto da sociedade, em que impera o modo de produção capitalista, pressupõe uma necessidade permanente de "qualificação profissional". Contudo, é intensificado o questionamento em torno das políticas de educação atuais, especificamente as gestadas e materializadas pela Rede Federal de Educação Profissional e Tecnológica, que dispõe sobre a instituição a qual se destinou este estudo. Reconhecendo os processos históricos das instituições de Educação Profissional em nossa sociedade, é válido pensar se esta nova instituição contribuirá para o fortalecimento ou para uma transformação que leve à constituição de alternativas para a superação da ordem econômica e social estabelecida nesta sociedade.

\title{
À GUISA DE CONCLUSÃO
}

Este texto foi produzido no intuito de considerá-lo como mais uma oportunidade de retorno social de uma pesquisa, a qual foi apoiada pela instituição em que a mesma 
foi realizada, considerando as condições favoráveis para que a pesquisadora, que é Técnica-Administrativa em Educação, realizasse tal estudo, e, assim, contribuísse com a produção de uma possível práxis pedagógica. Pois as dimensões de ordem teórica passam a subsidiar e consubstanciar uma prática cotidiana que possibilite a realização de um trabalho pedagógico mais consciente. E assim lance possibilidades para contribuir com uma reflexão mais crítica em torno das políticas públicas que atravessam os processos de consolidação institucional da educação profissional e tecnológica.

Não se pode negar que os Institutos Federais possuem uma historicidade, apesar de apresentarem um novo ordenamento político e pedagógico a partir do ano de 2008 , com a Lei $n^{\circ} 11.892$, a qual cria a Rede de Educação Profissional e Tecnológica. Na concretude, os IFs contemplam uma significativa especificidade que os diferencia das demais instituições públicas de educação brasileira, as escolas de Educação Básica ou as de Ensino Superior. Os Institutos Federais estão se constituindo em lugares de realização tanto da Educação Básica, Ensino Superior e Pós-Graduação, atendendo ainda uma multiplicidade de programas educativos para a população que vive no mundo do trabalho, tendo ainda em seu projeto pedagógico o compromisso com a articulação entre o ensino, a pesquisa e a extensão.

É mister considerar que a implantação destas instituições está atrelada à relevantes investimentos financeiros tanto nas estruturas físicas (prédios, laboratórios, equipamentos, entre outros) quanto de recursos humanos bem qualificados, pois é aparente a existência de um aumento significativo no número de profissionais, professores e técnicos-administrativos em educação. Estas percepções (ainda que em uma dimensão empírica), possibilita um espaço para muitas inquietações e indagações sobre o que está se produzindo no âmbito destas instituições, considerando as dimensões pedagógica, do trabalho, da ciência e da tecnologia. Que ciência, que tecnologia, os trabalhadores dos Institutos Federais têm produzido? A educação idealizada e realizada está contribuindo com a formação de que cidadãos? De que aprendizagens? Tem provocado transformações sociais de que ordem?

É extremamente necessário compreender os múltiplos movimentos políticos e sociais pelos quais as categorias trabalho e educação perpassaram ao longo da história da sociedade capitalista. Haja visto que os discursos políticos mascaram uma realidade latente no percurso histórico da educação brasileira, forjando uma escola destinada a todas as crianças, todos os jovens e adultos, homens e mulheres que vivem do trabalho nesta sociedade. Há de se considerar que este sistema de produção capitalista exerce 
severas influências nas políticas públicas de educação e na dinamização das instituições de educação e no trabalho de seus trabalhadores. Ter consciência desta realidade pode viabilizar novas maneiras de ser e estar no mundo, possibilitando aos trabalhadores realizar um trabalho mais humano e digno.

\section{REFERÊNCIAS}

ANTUNES, Ricardo. Adeus ao trabalho?: Ensaio sobre as metamorfoses e a centralidade do mundo do trabalho/ Ricardo Antunes. - 15. Ed. - São Paulo: Cortez, 2011.

BRASIL. Ministério da Educação. Concepção e Diretrizes do Instituto Federal de Educação, Ciência e Tecnologia, Brasília, DF, 2008.

Lei $\mathbf{n}^{\mathbf{0}} \mathbf{1 1 . 8 9 2}$, de dezembro de 2008.

CIAVATTA, Maria. Mediações do mundo do trabalho, a fotografia como fonte histórica. In: LOMBARDI, J.C.; SAVIANI, D; SANFELICE, J. L. (orgs.) Capitalismo, trabalho e educação. SP: Cortez Autores Associados, 2005.

CIAVATTA, Maria. Memórias e temporalidades do trabalho e da educação / Maria Ciavatta (Coord.); Eliza Tavares Duarte... [et AL.]. - Rio de Janeiro: Lamparina: Faperj, 2007.

FOGAÇA, Azuete. "Educação e qualificação profissional nos anos 90: o discurso e o fato. In: OLIVEIRA, D. A; DUARTE, M. R. T. Políticas e trabalho na escola Administração dos sistemas públicos de Educação Básica.Belo Horizonte: Autêntica, 2003.

GENTILI, Pablo. Três teses sobre a relação trabalho e educação em tempos neoliberais. In: LOMBARDI, J.C.; SAVIANI, D; SANFELICE, J. L. (orgs.) Capitalismo, trabalho e educação. SP: Cortez Autores Associados, 2005.

LUCENA, Carlos. Marxismo, crise do capitalismo monopolista e qualificação dos trabalhadores. In.: Marxismo e Educação: Debates contemporâneos/José Claudinei Lombardi, Demerval Saviani (orgs.). Ed. - Campinas, SP: Autores Associados: HISTEDBR, 2008.

MANFREDI, Silvia Maria. Educação Profissional no Brasil / Silvia Maria Manfredi. São Paulo: Cortez, 2012.

MARX, Karl, 1818 -1883. O Capital: crítica da economia política: livro I / K ARL Marx; tradução de Reginaldo Sant'Anna. 30ªed. Rio de Janeiro: Civilização Brasileira, 2012. 2v.

MARX, Karl; ENGELS, Friedreichi. 1818 - 1883. Textos sobre Educação e Ensino. Karl Marx e Friedrichi Engels. Tradução de Rubens Eduardo Frias. São Paulo:

Centauro, 2004. 
MÉSZÁROS, István, 1930. A educação para além do capital. István Mészáros; [tradução Isa Tavares]. 2.ed. - São Paulo: Boitempo, 2008.

MÉSZÁROS, István. Estrutura social e formas de consciência, volume II: a dialética da estrutura da história / István Mészáros; tradução Rogério Bettoni; revisão técnica Caio Antunes. - São Paulo: Boitempo, 2011.

KOSIK, Karel. Dialética do Concreto, 2ª ed., São Paulo: Paz e Terra, 1976.

RUMMERT, S. M. ALGEBAILE E. VENTURA, J. Educação e formação humana no cenário de integração subalterna no capital imperialismo. Disponível em:

$<$ http://www.uff.br/ejatrabalhadores/ANPED.pdf $>$. 34 ${ }^{\text {a }}$ Reunião Anual da ANPEd, 2011.

SANFELICE, José Luis. Dialética e Pesquisa em Educação. In.: Marxismo e educação: debates contemporâneos/José Claudinei Lombardi, Demerval Saviani (orgs.).- 2.ed.-Campinhas, SP: Autores Associados: HISTEDBR, 2008.

SAVIANI, Demerval. Instituições Escolares no Brasil: conceito e reconstrução histórica. In: Instituições Escolares no Brasil: conceito e reconstrução histórica/ Maria Izabel Moura Nascimento... [et al.], (orgs.). - Campinas, SP: Autores Associados: HISTEDBR; Sorocaba, SP: UNISO; Ponta Grossa, PR: UEPG, 2007.

SAVIANI, Demerval. Transformações do capitalismo, do mundo do trabalho e da educação. In: LOMBARDI, J.C.; SAVIANI, D; SANFELICE, J. L. (orgs.)

Capitalismo, trabalho e educação. SP: Cortez Autores Associados, 2005.

PACHECO, Eliezer. Institutos Federais uma revolução na educação profissional e tecnológica. /Organização, Eliezer Pacheco. Editora Moderna Ltda. São Paulo, 2011.

ISBN 978-85-16-07375-6

PACHECO, Eliezer; SILVA, Caetana Rezende. Institutos Federais: um futuro por armar. In.: Institutos Federais lei 11.892, de 29/11/2008: comentários e reflexões / organização, Caetana Juracy Resende Silva. - Nata: IFRN, 2009.

SILVA, Caetana Resende. Institutos Federais lei 11.892, de 29/11/2008: comentários e reflexões / organização, Caetana Juracy Resende Silva. - Nata: IFRN, 2009.

\section{Como referenciar este artigo}

CEZAR, Taise Tadielo.; FERREIRA, Liliana Soares. A relação entre educação e trabalho: um contexto de contradições e a aproximação com a educação profissional. Revista Ibero-Americana de Estudos em Educação, Araraquara, v. 11, n. 4, p. 2141 2158, 2016. Disponível em: <http://dx.doi.org/10.21723/riaee.v11.n4.8248>. E-ISSN: $1982-5587$.

Submetido em: dezembro/2015

Aprovação final em: outubro/2016 